\title{
UNREPORTED INJURIES IN THE MARTIAL ARTS
}

\author{
Richard B. BIRRER, MD and Christina D. BIRRER, MS \\ East New York Neighbourhood Family Care Center, \\ 2094 Pitkin Avenue, Brooklyn, NEW YORK, NY 11207
}

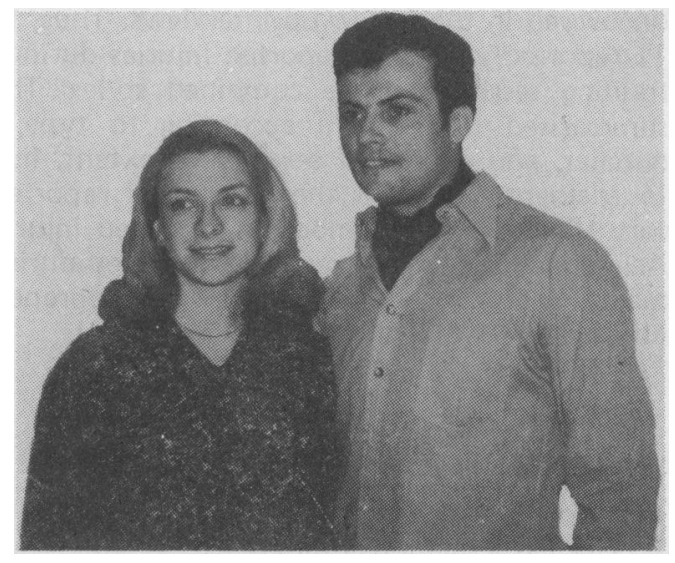

To date there has been little data available regarding the safety and injury statistics in the sports referred to collectively as the Martial Arts which includes any of the Eastern methods of hand combat or self-defence: Judo*, Aikido, Jiujitsu, Kung Fu, Karate, Tae Kwon Do, etc. Much of the information is not too useful since it is several decades old and is derived from studies done primarily in Japan (Nakata and Shirahata, 1943). Over the last decade Martial Arts has enjoyed a remarkable degree of acceptance and growth spurt in America and Great Britain. The estimated number of athletes actively participating in the sport is about 200,000 with a 5:1 male to female ratio. One large international survey has shown that the risk of serious injury is small (less than $0.2 \%$ ) and that the majority of reported injuries are mild to moderate in nature and consist of sprains, strains, contusions, and minor lacerations (Birrer and Birrer, 1982). The incidence of injury is higher in the tournament situation in which in 1976 there was some form of injury in every 4 contests and an incapacitating injury every ten contests (McLatchie, 1976). A wide range of trauma has been recorded and though rare, life threatening injuries to the head, thorax, and abdomen have occurred (Kurland, 1980; Cantwell and King, 1973). In order to elucidate the full extent and impact of injuries in the Martial Arts we surveyed a number of athletes during and after tournament and training sessions in order to determine the number and quality of sports-related injuries.

\section{METHOD}

Three training halls were chosen in the New York City region for the study. The represented styles were: Shotokan, Karate, Tae Kwon Do, and Kung Fu. Forms, fighting, breaking, and weapon usage were observed in each style. Three training sessions over a two week

\footnotetext{
* Judo is not considered a Martial Art in Britain.
}

period in each studio were attended by the authors during which time all observed injuries were, unknown to the athlete, catalogued according to site, number, type, and extent. All athletes were notified in advance that a doctor would be present and could be consulted about sports medicine problems. All such consultations were recorded under the "reported" column. After each of the three sessions all athletes were interviewed confidentially concerning any injury which the athlete had suffered during the workout. At the same time, the athlete was confronted with injuries observed by the interviewer but not reported during the session itself. These injuries were recorded as "unreported". A discussion elucidating in detail both the reported and unreported injuries followed and the reasons for the discrepancies. All results were thus tabulated as reported vs unreported and observed vs interviewed.

A similar study was performed during tournament conditions in which athletes from the three participating training halls were observed during three different competitions. The contest rules in all three were the same: no contact to the head and neck and light contact to the anterior trunk; the use of groin cups, mouth guards, and safety punch and kick devices were mandatory. One of the authors was physician-in-charge of each of the contests. All injuries were categorised into "reported" or "unreported-observed". Post-tournament interviews were conducted in the same manner as above in order to follow-up reported and observed injuries. No attempt was made to compare injury number or type between the different styles.

\section{RESULTS}

A total of 57 athletes (49 males and 8 females) were followed in the three training halls through the entire study. A total of 11 injuries were reported in the three training sessions. An additional 13 injuries were observed during the same period and an additional 7 injuries were 
uncovered in the follow-up interviews. Thus, there were 11 reported and 20 unreported injuries during the three training sessions in the combined styles. The data is summarised in Table I according to type, location, number, and degree of severity or extent. In the three tournament situations the number of reported injuries was 18 while the number of observed injuries was 1 . An additional 12 injuries were reported during tournament conditions and $\mathbf{3 0}$ injuries were unreported. The tournament data is summarised in Table II.

\section{TABLE I}

\section{REPORTED}

Mild-moderate contusion (trunk)

Mild-moderate sprain of digits

Mild strain lower back/lower extremity

Minor skin laceration

Mild contusion head/neck

Total

\section{UNREPORTED}

Mild contusion groin/digit

Mild-moderate contusion of shin

Mild contusion of head/neck

Mild strain hamstrings

Sprain of digit

Minor laceration

Mild contusion (trunk)

Total

$\begin{array}{cc}\text { Observed } & \text { Interviewed } \\ 2 & - \\ 2 & 2 \\ 3 & - \\ 1 & - \\ - & 2 \\ - & 1 \\ 5 & 2 \\ 13 & 7\end{array}$

The total combined number of injuries was 79 of which 29 (36.7\%) were reported and 50 (63.3\%) were unreported.

\section{DISCUSSION}

Several important observations can be derived from this study.

First, a high percentage (63\%) of injuries related to the Martial Arts are not reported. We suspect that this is a conservative figure because the athletes may also have forgotten some minor injuries during the interview which were not observed during the training session studied, or during competition. Furthermore, it is quite possible that some athletes wilfully withheld information even during the interview for several reasons: feelings of invulnerability (a frequently taught trait in the Martial Arts), fear or anxiety about the instructor's perception of injury, or confusion as to the definition of an injury.

Second, in comparing observed to interviewed categories of unreported injuries it was noted that two factors were important. The pain threshold was often

\section{TABLE II}

\section{REPORTED}

Moderate contusions

Mild contusion head/neck

Fracture

Moderate laceration

Concussion

Moderate sprain (digits, ankle, writst)

Miscellaneous (wind knocked out)

Total

$\begin{array}{cc}\text { Observed } & \text { Interviewed } \\ 1 & - \\ 8 & 5 \\ 1 & 1 \\ 1 & 1 \\ - & 1 \\ 2 & 2 \\ 2 & 1 \\ 3 & 1 \\ 18 & 12\end{array}$

UNREPORTED

Concussion

Mild contusion (trunk/groin/

extremities)

Minor laceration

Dislocation (digit/shoulder)

Fracture

Mild-moderate sprain

Mild-strain

Miscellaneous $(2$ chest +2

abdominal strikes)

Total

Total number of injuries $=79$

Total number reported $=29(36.7 \%)$

Total number unreported $=50(63.3 \%)$

Observed $=41$

Interviewed $=19$

raised in the Martial Arts athletes, particularly amongst the advanced students, and very often, ignorance of the severity of the injury was prominent. Thus, more unreported injuries were observed than actually obtained by interview, and when the athletes were confronted by observations, the above factors were primarily (distortion of pain threshold and ignorance) responsible, though the same factors in the withholding of information voluntary probably also entered the picture.

Third, injuries tended to be more severe overall in tournament situations than during training; a fact in keeping with previous studies. The overall tournament percentages of reported and unreported did not differ significantly from the training group. However, head injuries were not only more common in contests, but also more frequently reported which probably reflects the fact that a competing athlete could be disqualified for a head/neck strike. Such head strikes, though milder in training conditions, also tended to be ignored; i.e. unreported.

Fourth, potentially serious injuries were unreported in both training and particularly in competition. For 
instance, there was an unreported moderate third metacarpophalangeal joint contusion observed in a training session which showed no fracture on $\mathrm{X}$-ray but required 4 weeks to heal due to poor compliance, with the result that there remained a deformed joint with $85 \%$ function. Regarding the tournament situation potentially serious unreported injuries included: 1 concussion, (fight was stopped through observation), 2 dislocations (shoulder and distal phalangeal joint - the former was reduced by the athlete himself while the latter was done by friends), 2 moderately severe abdominal blows, and 1 fractured 5th metatarsal discovered two days after the meet. Fortunately, most of these injuries were observed at the time of their occurrence, but nonetheless, several were not. The consequences were not minimal. The missed dislocation of the distal interphalangeal joint turned out to have an associated avulsion fracture, and one of the abdominal strikes of the left upper quadrant necessitated an emergency room visit 6 hours after the contest for diagnostic evaluation for a possible rupture of the spleen. The discharge diagnosis was rib contusion.

\section{CONCLUSION}

The implications of this study are important not only for Martial Arts but also for other sports. Under-reporting of injury data is a major problem since it does not allow an accurate estimate of the risks and safety of a sport, and sometimes, places the involved athlete in danger of significant injury. Thus, at least 63 Martial Arts injuries are not reported irrespective of conditions (regular training versus tournament competition). Some of the unreported injuries are particularly hazardous in terms of short term as well as long term effects. Physicians who cover these events must be aware of the injury spectrum in this sport as stated by McLatchie in 1979a, $1979 \mathrm{~b}$ and before that by McLatchie and Morris in 1977 when discussing injuries and their prevention in Karate.

\section{ACKNOWLEDGEMENTS}

The authors express their gratitude to Ms. Roberta Hilbert, Principal Administrative Associate for typing assistance.

\section{REFERENCES}

Birrer, R. and Birrer, C., 1982 “Martial Arts injuries". Phys. and Sports Med. 10 (6): 103-108.

Cantwell, J. D. and King, J. T., 1973 "Karate chops and liver lacerations". JAMA 224: 1424.

Kurland, H., 1980 "Injuries in Karate". Phys. and Sports Med. 10: 80-85.

McLatchie, G. R., 1976 “Analysis of Karate injuries sustained in 295 contests". Injury 8: 132-134.

McLatchie, G. R., 1979a "Recommendations for Medical Officers attending Karate competitions". B.J.Sports Med. 13: 36-37.

McLatchie, G. R., 1979b "Surgical and orthopaedic problems in sport Karate". Medisport 1: 40-44.

McLatchie, G. R. and Morris, E. W., 1977 "Prevention of Karate injuries - a progress report". B.J.Sports Med. 11: 78-82.

Nakata, M. and Shirahata, N., 1943 "Statistical observation on injuries from Judo". Jap.J.Orthop.Assn. 18: 1146-1154. 